coronary syndrome risk model, the Global Registry of Acute Coronary Events (GRACE), in a PE cohort, as it contains important haemodynamic variables and target organ lesion markers providing an interesting assessment of illness severity. Although the results warrant further validation in independent cohorts, the GRACE seemed to accurately capture PE severity [10].

Acute PE is a complex condition with several organ-interactions, a broad clinical presentation and a wide prognosis. Currently, PE risk stratification schemes may perform satisfactorily at ruling-out illness severity and allow assessment of patient eligibility for outpatient management. The next step would be to correctly recognise truly high-risk normotensive $\mathrm{PE}$ cases that would benefit from early and more aggressive therapies, such as thrombolysis.

@ERSpublications

The next step for PE risk stratification will be to correctly recognise truly high-risk normotensive PE cases http://ow.ly/nSvxM

Luis Paiva, Sérgio Barra and Rui Providência

Coimbra's Hospital and University Centre, Coimbra, Portugal.

Correspondence: L. Paiva, Quinta dos Vales, 3041-801, S. Martinho do Bispo, Portugal. E-mail: luisvpaiva@gmail.com

Received: Feb 262013 | Accepted after revision: March 052013

Conflict of interest: None declared.

\title{
References
}

Sanchez O, Trinquart L, Planquette B, et al. Echocardiography and pulmonary embolism severity index have independent prognostic roles in pulmonary embolism. Eur Respir J 2013; 42: 681-688.

2 Aujesky D, Obrosky DS, Stone RA, et al. Derivation and validation of a prognostic model for pulmonary embolism. Am J Respir Crit Care Med 2005; 172: 1041-1046.

3 Sam A, Sánchez D, Gómez V, et al. The shock index and the simplified PESI for identification of low-risk patients with acute pulmonary embolism. Eur Respir J 2011; 37: 762-766.

4 Moores L, Zamarro C, Gómez V, et al. Changes in PESI scores predict mortality in intermediate-risk patients with acute pulmonary embolism. Eur Respir J 2013; 41: 354-359.

de Lemos JA, McGuire DK, Drazner MH. B-type natriuretic peptide in cardiovascular disease. Lancet 2003; 362: 316-322. Barra S, Paiva L, Providência R, et al. LR-PED rule: low risk pulmonary embolism decision rule - a new decision score for low risk pulmonary embolism. Thromb Res 2012; 130: 327-333.

7 Barra SN, Paiva LV, Providência R, et al. Atrial fibrillation in acute pulmonary embolism: prognostic considerations. Emerg Med J 2013 [In press DOI: 10.1136/emermed-2012-202089].

8 Takamura T, Dohi K, Onishi K, et al. Reversible left ventricular regional non-uniformity quantified by speckletracking displacement and strain imaging in patients with acute pulmonary embolism. J Am Soc Echocardiogr 2011; 24: 792-802.

9 Henzler T, Roeger S, Meyer M, et al. Pulmonary embolism: CT signs and cardiac biomarkers for predicting right ventricular dysfunction. Eur Respir J 2012; 39: 919-926.

10 Paiva LV, Providência RC, Barra SN, et al. Cardiovascular risk assessment of pulmonary embolism with GRACE risk scorê. Am J Cardiol 2013; 111: 425-431.

\section{Smoking resumption after lung transplantation: standardised screening and importance for long-term outcome}

To the Editor:

Worldwide, about $40 \%$ of lung transplantations (LTx) are performed for end-stage emphysema [1]. Eligible patients are enrolled on the waiting list after at least 6 months of smoking cessation [1]. Although in most centres smoking behaviour after LTx is not routinely monitored, resuming smoking can complicate posttransplant outcome [2-5].

In general, smoking relapse can be found in $12-40 \%$ of all liver, heart and renal transplant patients [3]. Smoking is mostly assessed by use of a questionnaire. Only the study of BoTHA et al. [4] combined a questionnaire with urinary cotinine detection. We previously reported post-LTx smoking in $11 \%$ of our 
LTx patients [6]. Patients that restart smoking after heart [4] and liver transplantation [5] have an increased prevalence of cancer, yet there are no data for LTx.

We assessed all living, mainly adult (98\%), LTx patients $(n=331$, of whom 230 were also included in our previous study [5]) with a minimal follow-up of 1 year after approval by the local Ethics Committee (approval number S51577) and informed consent. Smoking behaviour was investigated by a questionnaire, semi-quantitative and quantitative measurement of cotinine, and exhaled carbon monoxide levels. The questionnaire addressed past and current smoking habits. Second-hand smoking was defined as an living with a relative who smoked. The exhaled carbon monoxide level was quantified using an electrochemical sensor (Bedfont Scientific, Kent, UK) (detection limit $1 \mathrm{ppm}$ ) as previously described [5]. An exhaled carbon monoxide value $\geqslant 10 \mathrm{ppm}$ was considered positive.

Quantitative cotinine analysis was performed using ultra-pressure liquid chromatography, in combination with tandem mass spectrometry, using $\mathrm{d} 3$-cotinine as an internal standard. Cotinine values of $>7.5 \mathrm{ng} \cdot \mathrm{mL}^{-1}$ were detected and a value $>75 \mathrm{ng} \cdot \mathrm{mL}^{-1}$ was considered positive. Semi-quantitative cotinine measurements were assessed by gas chromatography and mass spectrometry (Thermo Scientific, Geel, Belgium) as previously described [5]. Graph prism software (version 4.0; San Diego, CA, USA) was used for statistical analysis.

Where appropriate, Mann-Whitney or Chi-squared tests were used for analysis of patient characteristics. For multivariate analysis, stepwise regression was used (SAS 9.3; SAS Institute Inc., Cary, NC, USA), including all clinically relevant and univariate significant variables.

Based on the questionnaire, 33 (10\%) out of 331 patients reported having smoked after LTx, whereas the remaining 298 patients denied smoking. 24 patients concurrently had positive cotinine levels and six out of 33 patients admitted having stopped smoking post-transplant, which was confirmed with negative cotinine detection. No urine could be collected in three of 33 post-LTx smokers due to anuric renal insufficiency. In the nonsmoking group (questionnaire), six patients had cotinine levels above the smoking limit and were therefore considered active smokers. Taken together, $39(12 \%)$ out of 331 patients resumed smoking after LTx, of whom $33(10 \%)$ were current smokers and six (2\%) were past smokers. Post-LTx smokers resumed smoking a median (interquartile range) of $1.5(0.8-3.0)$ years after LTx and smoked a mean (range) of 3 (3-6) cigarettes per day. Since 33 out of 39 post-LTx smokers admitted to a smoking relapse by means of the questionnaire, its sensitivity (85\%) and specificity (100\%) can be considered as "good".

Quantitative determination of urinary cotinine was available in 318 patients (missing data: anuric renal failure $(n=7)$, inadequate urine sample $(n=6))$. Cotinine values were under the detection limit in 262 patients. Cotinine levels were moderately elevated in 26 patients, with values above the detection limit $\left(7.5 \mathrm{ng} \cdot \mathrm{mL}^{-1}\right)$ and below the smoking limit $\left(75 \mathrm{ng} \cdot \mathrm{mL}^{-1}\right) .30(10 \%)$ patients had a strongly elevated cotinine level which was compatible with active smoking $\left(>75 \mathrm{ng} \cdot \mathrm{mL}^{-1}\right)$. The latter 30 patients also had positive semi-quantitative cotinine detection although there were six positive semi-quantitative cotinine results with a negative questionnaire, resulting in $100 \%$ sensitivity and $98 \%$ specificity of cotinine in our population. Median (interquartile range) exhaled carbon monoxide levels were higher in post-LTx smokers compared to nonsmokers: 8 (3-13) ppm versus $3(2-5)$ ppm $(\mathrm{p}<0.0001)$.

Smoking resumption was the highest in the emphysema group (36 (22\%) out of 167 patients), while this was overall very low in non-emphysema patients $(\mathrm{p}<0.0001)$ (table 1$)$. The abstinence period before LTx was shorter in patients who relapsed after LTx: 1.0 (1.0-3.0) versus 6.0 (2.0-10.5) years, respectively $(\mathrm{p}<0.0001)$. Smoking relapse post-LTx was not related to the pack-years pre-LTx (mean 28 pack-years in the post-LTx nonsmoking group compared to 31 pack-years in the smoking group) $(\mathrm{p}=0.26)$.

Second-hand smoking was higher in post-LTx smokers compared with nonsmokers $(\mathrm{p}<0.0001)$ (table 1$)$. The exposure to second-hand smoking and a shorter period of pre-LTx smoking abstinence were independent risk factors for smoking relapse after LTx in multivariate analysis $(\mathrm{p}<0.0001$, prevalence risk (PR) 5.42 and $\mathrm{p}=0.0008$, PR 1.18, respectively).

Oncological events were detected in $36(10 \%)$ patients (haematological, $n=13$; lung, $\mathrm{n}=10$; digestive tract, $\mathrm{n}=6$; urogenital, $\mathrm{n}=3$; brain, $\mathrm{n}=2$; other, $\mathrm{n}=2)$, of whom $23(7 \%)$ patients developed a solid tissue cancer. The prevalence of oncological events was higher in post-LTx smokers compared to nonsmokers $(p=0.0043$, PR 2.88). Solid organ cancer was especially more frequently diagnosed in post-LTx smokers compared to nonsmokers $(p=0.0024, P R$ 3.99). In particular, lung cancer was more prevalent in post-LTx smokers compared to nonsmokers $(\mathrm{p}=0.021, \mathrm{PR} 4.99)$. Time of diagnosis of the lung cancers was comparable in both groups $(p=0.82)$ (table 1$)$. Neither the number of pack-years $(p=0.43)$ nor the percentage of underlying chronic obstructive pulmonary disease (COPD) patients before LTx $(p=0.38)$ were different between the group with or without an oncological event. 
TABLE 1 Patient demographics of the 331 living patients

$\begin{array}{lc}\text { Patients } \mathbf{n} & 292 \\ \text { Type of LTx } & \\ \text { SSLTx } & 232(79) \\ \text { SLTx } & 43(15) \\ \text { Heart-lung } & 17(6) \\ \text { Underlying disease } & \\ \text { Emphysema } & 131(45) \\ \text { Cystic fibrosis } & 66(22) \\ \text { ILD } & 44(15) \\ \text { PAH } & 28(10) \\ \text { Other } & 23(8) \\ \text { Age years } & 52(37-58) \\ \text { Males } & 144(49) \\ \text { Smokers before LTx } & 178(61) \\ \text { Second-hand smoking } & 92(28) \\ \text { Oncological events } & 26(9) \\ \text { Solid tissue cancer } & 15(5) \\ \quad \text { Time to diagnose days } & 1460(432-2023) \\ \text { Lung cancer } & 6(2) \\ \quad \text { Time to diagnose days } & 2048(1185-2516)\end{array}$

$\begin{array}{cc}39 & 0.17 \\ 28(72) & 0.27 \\ 10(26) & 0.08 \\ 1(2) & 0.40 \\ & <0.0001^{*} \\ 36(91) & <0.0001^{*} \\ 1(3) & 0.0034^{*} \\ 0(0) & 0.0092^{*} \\ 1(3) & 0.15 \\ 1(3) & 0.23 \\ 54(49-57) & 0.062 \\ 20(51) & 0.82 \\ 39(100) & <0.0001^{*} \\ 33(75) & <0.0001^{*} \\ 10(26) & 0.0043^{*} \\ 8(20) & 0.0024^{*} \\ 1900(575-2555) & 0.16 \\ 4(10) & 0.021^{*} \\ 2448(1383-2851) & 0.61\end{array}$

Data are presented as $\mathrm{n}(\%)$ or median (interquartile range), unless otherwise stated. LTx: lung transplantation; SSLTx: sequential single lung transplantation; SLTx: single lung transplantation; ILD: interstitial lung disease; PAH: pulmonary arterial hypertension. *: p $<0.05$ was considered significant.

The current study demonstrated a high prevalence of post-LTx smoking, as $12 \%$ of our LTx population and even $22 \%$ of the emphysema patients resumed smoking post-LTx, confirming our previous work [5]. Peergroup smoking is an important risk factor for smoking resumption. Therefore, patients' relatives, who most often continue smoking, should also be recommended to stop smoking. Our study also showed that shorter cessation time before LTx was associated with smoking relapse after LTx. This could imply that an abstinence period of 6 months may actually be too short [7]. However, a longer abstinence period would be difficult to achieve in patients with, for instance, idiopathic pulmonary fibrosis, due to its worse prognosis.

Importantly, we demonstrated an increased prevalence of oncological events in patients who resume smoking post-LTx. The oncological effects of smoking are well known, and are even strengthened by postLTx immunosuppressive therapy [8]. Therefore, patients should be actively counselled concerning the possible negative health-effects of smoking resumption.

Although a questionnaire is subjective, it seemed to have a good sensitivity/specificity to detect smoking and correlated well with the urinary cotinine test, a more objective assessment of a patient's nicotine exposure. Besides being sensitive (100\%), semi-quantitative cotinine determination is also very specific (98\%). Because quantitative cotinine analyses are not available in clinical practice, we would recommend the semiquantitative cotinine detection method to be performed several times while on the waiting list and at least once a year after LTx, or whenever smoking resumption is suspected. However, the results of the exhaled carbon monoxide measurements showed a rather low sensitivity (48\%), which is probably due to its short half-life. Therefore, one should question the place of exhaled carbon monoxide determination in screening.

In conclusion, the prevalence of post-LTx smoking is higher than generally assumed and active screening, both pre- and post-LTx, is crucial to detect smoking resumption. A standardised questionnaire and repeated cotinine testing is probably the best screening method to detect post-LTx smoking. Implementing a standardised smoking cessation plan after LTx, as in COPD [9], and a longer pre-LTx cessation period (especially in COPD patients) should be considered, not only for patients but also for smoking relatives. Finally, for the first time a clear association between smoking resumption after LTx and an increased prevalence of oncological events was demonstrated.

@ERSpublications

The prevalence of post-LTx smoking is $12 \%$ with a short cessation period causing an increase in oncological events http://ow.ly/pPlwS 
David Ruttens ${ }^{1}$, Stijn E. Verleden ${ }^{1}$, Pieter C. Goeminne ${ }^{1}$, Katrien Poels ${ }^{2}$, Elly Vandermeulen ${ }^{1}$, Lode Godderis ${ }^{2}$, Dirk E. Van Raemdonck ${ }^{1}$, Bart M. Vanaudenaerde ${ }^{1}$, Jeroen Vanoirbeek ${ }^{2}$, Robin Vos ${ }^{1}$ and Geert M. Verleden ${ }^{1}$ ${ }^{1}$ Lung Transplant Unit, Laboratory of Pneumology, Katholieke Universiteit Leuven, University Hospital Leuven, Leuven, and ${ }^{2}$ Laboratory for Occupational and Environmental Hygiene, Center for Environment and Health, Katholieke Universiteit Leuven, Leuven, Belgium.

Correspondence: G.M. Verleden, Lung Transplant Unit, Laboratory of Pneumology, Katholieke Universiteit Leuven, University Hospital Leuven, 49 Herestraat, B-3000 Leuven, Belgium. E-mail: geert.verleden@uzleuven.be

Received: June 282013 | Accepted after revision: Aug 142013 | First published online: Aug 292013

Support statement: Funding of the research group includes the GlaxoSmithKline (Wavre, Belgium) Chair in Respiratory Pharmacology at the Katholieke Universiteit Leuven (Leuven, Belgium), and grants from the Research Foundation Flanders (Brussels, Belgium) (G.0723.10, G.0679.12 and G.0705.12) and the Katholieke Universiteit Leuven (OT10/050).

Conflict of interest: None declared.

\title{
References
}

1 Glanville AR, Estenne M. Indications, patient selection and timing of referral for lung transplantation. Eur Respir J 2003; 22: 845-852.

2 van der Heide F, Dijkstra G, Porte RJ, et al. Smoking behavior in liver transplant recipients. Liver Transpl 2009; 15: 648-655.

3 Corbett C, Armstrong MJ, Neuberger J. Tobacco smoking and solid organ transplantation. Transplantation 2012; 94: 979-987.

Botha P, Peaston R, White K, et al. Smoking after cardiac transplantation. Am J Transplant 2008; 8: 866-871. Vos R, De Vusser K, Schaevers V, et al. Smoking resumption after lung transplantation: a sobering truth. Eur Respir J 2010; 35: 1411-1413.

6 Herrero JI, Pardo F, D’Avola D, et al. Risk factors of lung, head and neck, esophageal, and kidney and urinary tract carcinomas after liver transplantation: the effect of smoking withdrawal. Liver Transpl 2011; 17: 402-408.

7 Orens JB, Estenne M, Arcasoy S, et al. Risk factors for cancer in renal transplant recipients. Transplantation 1999; 68: $1859-1864$

8 Sampaio MS, Cho YW, Qazi Y, et al. Post-transplant malignancies in solid organ adult recipients: an analysis of the US National Transplant Database. Transplantation 2012; 94: 990-998.

9 Warnier MJ, van Riet EE, Rutten FH, et al. Smoking cessation strategies in patients with COPD. Eur Respir J 2013; 41: 727-734.

\section{Can diaphragm pacing improve gas exchange? Insights from quadriplegic patients}

\author{
To the Editor:
}

Diaphragm pacing, as obtained by phrenic nerve stimulation through implanted electrodes, is a valid alternative to positive pressure mechanical ventilation (PPV) in patients with high spinal cord injuries [1]. Diaphragm pacing allows such patients to be weaned from PPV, but, to date, the respective effects of diaphragm pacing and PPV on gas exchange have not been compared. PPV is known to reduce ventilation in the lung bases [2]. By contrast, diaphragm pacing, like spontaneous breathing, should direct a larger proportion of the inspired volume to the lung bases. This should improve ventilation/perfusion matching. If this is the case, diaphragm pacing could be of interest as an adjunct to PPV in patients with lung injury. Indeed, in this setting, preserving diaphragmatic activity during mechanical ventilation can improve arterial oxygenation [3]. However, this can be difficult to achieve from a comfort point of view. In a proof-ofconcept perspective, we compared blood gases and energy expenditure during PPV and diaphragm pacing in 10 quadriplegics.

10 consecutive, stable and well-nourished tracheotomised quadriplegic patients were studied (six males, aged 15-46 years, mean $\pm \mathrm{SD}$ body mass index $21.9 \pm 4.0 \mathrm{~kg} \cdot \mathrm{m}^{-2}$ ). All had a phrenic nerve stimulator (Atrostim; Atrotech, Tampere, Finland) implanted at least 6 months earlier and were considered fully reconditioned. They were studied during planned routine visits, after approval of the ethics committee of the French Learned Society for Intensive Care Medicine. All patients gave their informed consent. Measurements were performed at least $3 \mathrm{~h}$ after a meal, with the tracheal cuff inflated. Oxygen consumption 